\title{
Borage (Borago officinalis) oil supplementation in relation to monocyte chemoattractant protein 1 expression in healthy subjects
}

\author{
M. Xiang ${ }^{1}$, E. Pinto ${ }^{1}$, M. A. Rahman ${ }^{1}$, M. Leach ${ }^{1,2}$ and L. S. Harbige ${ }^{1,2}$ \\ ${ }^{1}$ Centre for Biosciences Research, School of Science, University of Greenwich, Kent ME4 4TB, UK and ${ }^{2}$ Medway School of \\ Pharmacy, University of Kent and University of Greenwich, Kent ME4 4TB, UK
}

Essential fatty acids (EFA) have unique roles as precursor molecules of chemical regulators of inflammatory cell function ${ }^{(1-3)}$. In comparison with linoleic acid (18: $2 n-6), \gamma$-linolenic acid (GLA; 18: 3n-6) may have superior biopotency because the GLA bypasses the $\Delta 6$ desaturation, which is regarded as a key regulatory rate-limiting enzymic step controlling the formation of long-chain (LC) PUFA ${ }^{(4,5)}$. The present study investigated GLA-rich borage oil supplementation in relation to the monocyte chemoattractant protein 1 (MCP-1; CCL2) expression from peripheral blood mononuclear cells (PBMC) at the gene and protein levels in human subjects. Seven healthy volunteers who ingested $14 \mathrm{~g}$ borage oil/d consecutively for 13 weeks were studied. It was found that the MCP-1 production from both unstimulated and phytohaemagglutinin (PHA)-stimulated PBMC was reduced during the time-course of the intervention. Furthermore, MCP-1 from the PHA-stimulated PBMC decreased significantly during the 13 weeks of the intervention period. In addition, the level of PBMC $M C P-1$ gene expression was reduced significantly during the supplementation. A significant positive correlation was found between the expression of $M C P-1$ gene and MCP-1 production from both unstimulated $(r 0.40, P<0.05$; Figure (A)) and PHA-stimulated PBMCs $(r$ 0.66, $P<0.001$; Figure (B)).

The study has, for the first time, revealed that GLA-rich borage oil supplementation in human subjects results in the inhibition of PBMC MCP-1 expression at the gene and protein levels. The suppressive effect of GLA-rich borage oil on PBMC MCP-1 expression may be beneficial to chronic inflammatory diseases.
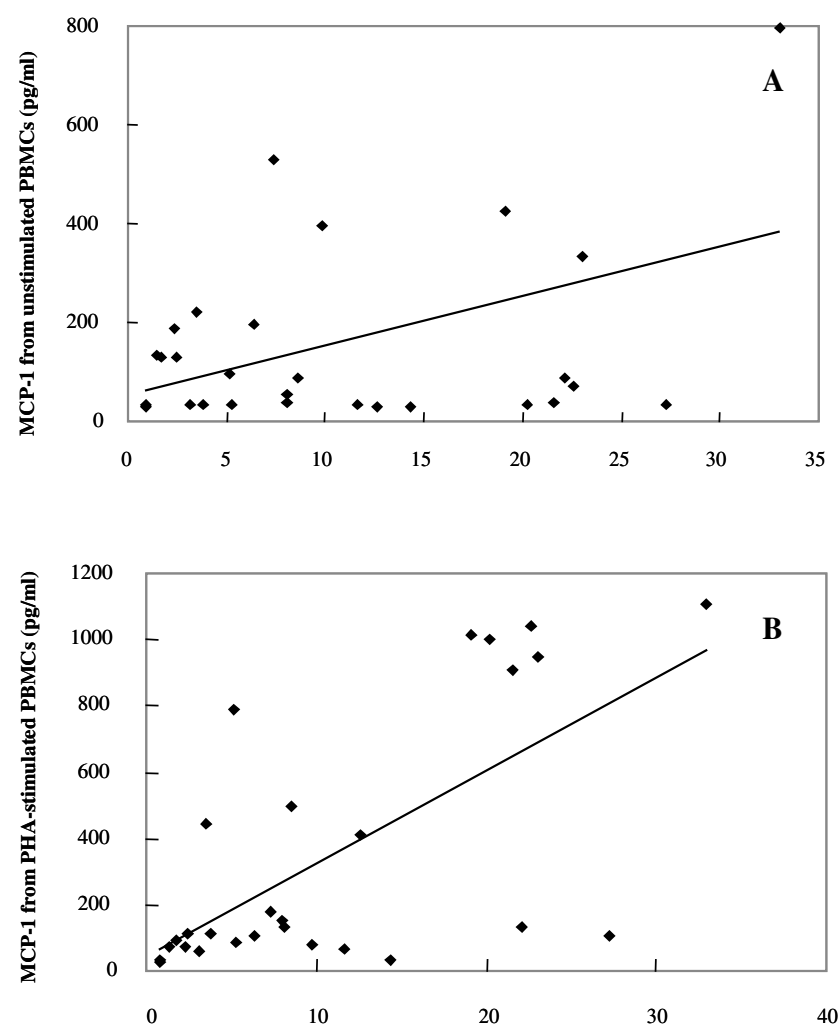

MCP-1 gene expression

2. Kast RE (2001) Int Immunopharmacol 1, 2197-2199.

3. Belch JJ \& Hill A (2000) Am J Clin Nutr 71, Suppl., 352S-356S.

4. Xiang M, Harbige LS \& Zetterstrom R (2007) Acta Paediatr 96, 387-390.

5. Xiang M, Rahman MA, Ai H, Li X \& Harbige LS (2006) Ann Nutr Metab 50, 492-498. 